\title{
Morals, Metaphysics and The Method of Cases
}

\author{
Simon Beck \\ School of Philosophy and Ethics \\ University of KwaZulu-Natal \\ Private Bag X01 \\ Scottsville, 3209 \\ South Africa \\ Email: beck@ukzn.ac.za <mailto:beck@ukzn.ac.za>
}

\begin{abstract}
In this paper I discuss a set of problems concerning the method of cases as it is used in applied ethics and in the metaphysical debate about personal identity. These problems stem from research in social psychology concerning our access to the data with which the method operates. I argue that the issues facing ethics are more worrying than those facing metaphysics.
\end{abstract}

\section{Introduction}

Metaphysics and moral philosophy (especially applied ethics) have both had chequered pasts in academic philosophy, going through periods of high regard and total dismissal. At the moment, applied ethics rides high while metaphysics is in a far more contentious position. I want to argue that this picture is unfair, at least as far as an important area of overlap between the two is concerned. Both rely heavily on appeals to imaginary cases. My overall argument will be that, in the light of a set of problems that emerge for this method from research in social psychology, metaphysics can defend itself with far more confidence than can ethics.

\section{Section 1: The method of cases in metaphysics}

... should the soul of a prince, carrying with it the consciousness of the prince's past life, enter and inform the body of a cobbler, as soon as deserted by his own soul, every one sees he would be the same person with the prince, accountable only for the prince's actions: but who would say it was the same man?

(Locke 1975: 44)

Imaginary cases occur widely in metaphysics, but no more frequently anywhere than in the context where this example of John Locke's comes from - the personal identity debate. It makes some sense, then, to take that context as a focus. Locke's own case makes a useful starting point in investigating the method of cases and the problems it may face.

In his debate with Locke, Leibniz points the way: "These bizarre fictions have their uses in abstract studies, as aids to a better grasp of the nature of our ideas" (Leibniz 1981: 314). Locke acknowledges that "in the ordinary way of speaking, the same person, and the same man, stand for one and the same thing" (Locke 1975: 44). But we 
must be prepared to go beyond the ordinary way when we inquire into "what makes the same person". As a start we must "fix the ideas of ... man, or person in our minds, and having resolved what we mean by them, it will not be hard to determine in either of them ... when it is the same, and when not" (Locke 1975: 44). Do 'same man' and 'same person' then really stand for the same thing? Our intuitions, once tested, show otherwise: "every one sees" that the cobbler-man is a different person after the soul swap; a different person, but the same man. Locke takes the result to be a blow against the Aristotelian tradition that places personal identity in being the same human animal. The identity conditions attached to our concept of man are shown to be different from those attached to our concept of person.

The method does not seem to have changed much since Locke. Nowadays, the corresponding thought-experiment opts for the use of technology and we are asked to imagine psychologies being moved between bodies by a brain-state-transfer device: a device which scans brains for all the information stored there, wipes other brains clean of information, and inputs the stored information into the cleared brain (Shoemaker 1984, following Williams 1973a). As before, we are confronted with a body exhibiting someone else's psychology - apparently remembering that other person's experiences, having their beliefs, desires, projects, emotional attachments and so on, and all of this as the causal result of that other person's actual experiences. Souls are no longer the transfer mechanism, but Locke would draw the same conclusion: faced with this scenario, we would say that this human being is now a different person, responsible for that other person's actions. Our intuitive response to the imaginary case is taken to show that a particular metaphysical theory - in this case, that personal identity is constituted by bodily or animal identity - is false.

In Section 5 I will suggest that our understanding of exactly how the method of cases works (if it is to work) needs some added sophistication, but these examples serve to give the general idea. It is worth noting here, though, that there is another way in which imaginary cases are used in the literature that I will not concern myself with. That is where the cases are not used as devices to draw out intuitions, but instead as heuristic devices to reveal a contradiction within some theory. Thomas Reid's "gallant officer" counter-example to Locke's theory would be a case in point (Reid 1975: 114). While these can be the basis for extremely important arguments, ${ }^{1}$ they reflect a distinctly different method, and are not threatened by the problems I wish to discuss in this paper.

\section{Section 2: The method of cases - ethics}

The use of imaginary cases in ethics is also extremely widespread, even if they do not dominate philosophy there as they do in the personal identity debate. Examples will be familiar to all of you. A classic to jog your memories is Williams's case of Jim and the Indians (Williams 1973: 98-99). Jim is faced with the choice of shooting an Indian villager and thereby freeing nineteen others, or refusing to shoot in which case all twenty will be killed by the dictator who has captured them. Jim has no other options - what should he do? Williams argues that in this case utilitarian moral theories imply that the obvious answer is that Jim should shoot the one and save the nineteen. But in this they would be wrong - our intuitions are that perhaps it is right that Jim should shoot, but

1 In my 'Points of concern' (Beck 2000), I suggest that Derek Parfit's 'My Division' thought-experiment (Parfit 1984: 254-5) should be seen as falling into this category, and that a failure to recognise this can lead to (and has led to) misguided criticism. 
not that this is obviously the right thing to do - and thereby a flaw is revealed in utilitarianism.

Their use is wider still - from trolley cases to fables and biblical parables, and their content can be far stranger. Thus Judith Jarvis Thomson offers as part of her defence of abortion, the analogy of this case:

Let me ask you to imagine this. You wake up in the morning and find yourself back to back in bed with an unconscious violinist. A famous unconscious violinist. He has been found to have a fatal kidney ailment, and the Society of Music Lovers has canvassed all the available medical records and found that you alone have the right blood type to help. They have therefore kidnapped you, and last night the violinist's circulatory system was plugged into yours, so that your kidneys can be used to extract poisons from his blood as well as your own. The director of the hospital now tells you, “... To unplug you would be to kill him. But never mind, it's only for nine months. By then he will have recovered from his ailment, and can be safely unplugged from you". ... I imagine you would regard this as outrageous. (Thomson 1979: 132)

Thomson offers the case and our responses to it as a refutation of the principle that the right to life always outweighs somebody's rights concerning what happens in and to their body. It also serves, though, as a neat example of another use of imaginary cases - where we set up an imaginary case to which we have a clear response in order to help us form a response to an analogous real case that we find difficult.

\section{Section 3: The authority of intuitive responses to cases}

At least on the face of things, ${ }^{2}$ both fields rely on intuitive responses to provide evidence - for or against some general principle or for the relevance and relative importance of certain properties. In this, our intuitive responses to particular cases are assumed to have a position of authority - just as, in our commonsense and scientific practice regarding the world around us, our particular observations are taken as authoritative. The question as to whether our intuitions can provide the authority required of them is a crucial one, however. I want to start investigating this issue by focussing on cases in moral philosophy, and in subsequent sections I will extend the discussion to include cases in metaphysics.

The analogy between observation in science or commonsense and intuitive responses to cases seems the obvious place to look in grounding the authority of the latter. Some moral philosophers make this claim explicitly in terms of our "seeing", for example, the rightness or wrongness of some act (Harman, 1977: 5; Thomson 1986: 257; Sober 2001: 413). There seems much to back up the comparison. Shelley Kagan has provided a neat account of this, and I am indebted to that in what follows (Kagan 2001). In observation, we see some event occur and we require that an empirical theory must explain this event. Should what we observe run counter to a given theory, we are moved to reject that theory or at least require its alteration. This does not mean that observation has to be taken as infallible - there can be all sorts of reasons for rejecting a particular observation. Observations nevertheless carry a great deal of weight, and have a position of epistemic priority over general principles and theory.

2 This will be an important qualification. In Section 5 I will argue that there is another way of understanding the method of cases. 
By analogy, intuitive responses to cases are in the position of observations. We "see" that some feature of a case is morally relevant or that some action is wrong. Moral theory is called upon to explain or account for this data, and should our intuitions run counter to what a theory implies about a case, we are moved to dismiss it or to require that it be changed in some appropriate way. As with observations, any particular intuition may be rejected in the light of other evidence - it may, for instance, have been registered under less than ideal conditions (such as when you were cross).

The practice of the method of cases thus mirrors observation in relevant and important ways. But this fact alone (as Kagan has pointed out) does nothing to justify our granting of authority to intuitions. It may seem to do so, since the analogy is to observation which is such a basic epistemological institution and obvious source of knowledge. But is only an obvious source of knowledge because we have good reason to accept our observations as reliable indicators of the world. Our sensory apparatus yields information that is (on the whole) to be trusted, and it is because this information is reliable that empirical theory must answer to it. So intuition only receives any justification from the analogy to observation if we have good reason to take our intuitions as reliable indicators of moral truth. And that is a very big "if". We can rely on our senses because we can provide a larger picture that explains how our senses "track the truth" by responding to features of reality. We have no parallel theory we can appeal to that gives a similar place to and explanation of our "moral sense". The problem is larger than this one that Kagan has isolated. It is not simply that we have no independent reason to take our intuitions as reliable; in the next few sections I will examine arguments to the effect that we have reason to see them as extremely unreliable.

\section{Section 4: Problems with authority}

When it comes to the method of cases in metaphysics, the situation seems similar to that in moral philosophy. Locke says that "everyone sees" that the person in the cobbler's body is the prince. But he is talking about intuitive responses rather than any other sort of seeing, and we will need some larger theory that explains the reliability of these intuitions if they are to have any sort of authority as indicators of metaphysical truth. The central problem I wish to raise is - at least on the first glance - directly concerned with using cases to investigate the self. I will spell out the problem first as it relates to metaphysical issues, then return to ethics and its relevance to our intuitions there.

One possible - and disturbing - reason for being suspicious of the reliability of our intuitive responses comes from empirical research in psychology. John Doris and Shaun Nichols have recently presented extended arguments as to how results in social psychology affect moral philosophy (Doris 2002; Nichols 2004); my argument will touch on some points similar to those raised by Nichols, but will raise distinct problems for the method of cases in both ethics and metaphysics.

The empirical research that I refer to comes, like Doris's and Nichols', from social psychology. Some recent work concerning the self appears to impact directly on the method of cases. Thought-experiments in the metaphysics of personal identity hinge on what we think about ourselves; empirical research tells us that much of what we believe about ourselves is in fact false, or at the least misleading.

What we tell ourselves we would say in as yet unactualized conditions is not necessarily what we would say; in fact it is probably not what we would say. This is the unavoidable conclusion from a great deal of experimental evidence. The evidence sug- 
gests that it is by no means the case that the healthy mind - reflecting the "commonsense view' - is the mind with an accurate view of reality, either external or, as is more pertinent to our thought-experiments, internal. Rather, the healthy mind is one with an unrealistically positive view of the self (Taylor and Brown 1988: 196). Most normal subjects tested regard their positive characteristics to be those most characteristic of themselves - more so than of the average individual. They also find those far easier to recall and process than negative ones (Brown 1986). Negative personal characteristics tend to go either unacknowledged or are dismissed as unimportant - as being more characteristic of the average individual than of yourself, and as not being influential in your behaviour. And it is not just that we see ourselves as better than average; we see ourselves as better than the evidence suggests we are, and certainly as better than others see us.

Striking evidence that our beliefs about ourselves are unreliable along these lines comes from the work of Lewinsohn and others (Lewinsohn, Mischel, Chaplin and Barton: 1980). Their findings are that observers watching subjects perform group interaction tasks and asked to rate the subjects on a number of personality characteristics consistently rated the subjects significantly more negatively than the subjects rated themselves on the same characteristics. All this suggests that we are not reliable judges of how we would behave - we ignore our negative traits and play up our positive ones in thinking about ourselves. So despite what we report to the thought-experimenter, we may well not be brave enough to enter the brain-state-transfer device (or whatever we say we would do) when the time came. Locke would take your saying that you would enter the device as revealing that you think you would emerge as one particular survivor, while all it may reveal is your boastfulness.

The problem is not just that we are sometimes wrong about ourselves, and the sort of people we are. The method of thought-experiment appears to assume a notion of the individual mind in which the experiment is to take place that is at odds with the evidence about those individual minds. If we are to introspect - to 'look inwards' - and find out how we would respond in an imagined situation, then we need to have access to the workings of our own minds. But it is precisely this that the evidence shows to be lacking. We may either have no access to the relevant data, or we may mislead ourselves about the data. Our minds may be healthy, but they are nevertheless prone to systematic self-delusion.

Nisbett and Ross point to other evidence as to how our introspected intuitions can be misleading and which seems to show that they are simply unreliable in the authoritative role that the method of cases assigns to them (Nisbett and Ross 1980: 226). The method gets to the metaphysics of the self by asking us how we respond to, or to judge what we would say in, as yet unactualized situations. The idea is that we know by introspection why we respond as we do to circumstances, so we can either say what is significant in those circumstances or we can predict on those grounds how we would behave in the newly envisaged circumstances. Nisbett and Ross's evidence disturbs this picture by showing that we do not know why we respond as we do: we tend to misdiagnose what underlies our responses. For instance, subjects deny the influence on their responses of factors which are indeed playing a significant role. Nisbett and Ross describe an experiment ${ }^{3}$ in which subjects - people shopping in a mall - are asked to compare the quality of various items of the same kind (nightgowns and panty-

3 This is just one of many experiments illustrating our misdiagnoses of what is causally relevant in our responses. 
hose in this case). Their responses show that the position of the items has a strong effect on these ratings - items on the right were preferred to items on the left, even though the items were identical in terms of their make-up. But the subjects had no introspective access to this, their introspections revealing other reasons for their responses:

When questioned about the effect of the garments' position on their choices, virtually all subjects denied such an influence (usually with a tone of annoyance or of concern for the experimenter's sanity). (Nisbett and Ross 1980: 207)

This is by no means an isolated example. Other experiments show that we not only are unaware of important influences on our responses, but also report with assurance on the influence of factors which the evidence suggests are not in fact influential - or certainly not in the way we introspect them to be. Nisbett and Ross report on an experiment that bears strikingly on our current concerns - on how our intuitive responses to a story are not to be relied upon. In the experiment, subjects were presented with a harrowing passage from John Updike's novel Run, Rabbit, Run which usually strongly affects its readers and asked to report on various aspects of the emotional impact that it had on them. One group was given the complete passage, another group was given the passage with two sections left out. When they rated the emotional impact of the passage they had read, there was no significant difference between how they were affected. When those in the group with the full passage were asked to rate the effect of the two parts that had been left out for the others on the impact of the whole piece, they $(86 \%$ of them in the case of one part) insisted that those two parts had substantially influenced their reaction. Introspection was misleading as to what it was that they were responding to or why they responded as they did, nor can we rely on it to reveal this for us.

As a result, we need to come to terms with the fact that what we think we are responding to or what we would say in as yet unactualised circumstances may bear little relation to what we in fact would say in those circumstances. Thought-experiments are held to rely on our making just such a prediction - we are asked to predict what we would say if, for example, a prince and a cobbler's psychologies swapped bodies. All this makes things look bleak for the method of cases in metaphysics.

While the research I have described concerns the self, it is not hard to see that it has a potential impact on the method in moral philosophy as well. A number of the examples mentioned involve subjects making intuitive judgements that appear to be of the same kind as those appealed to in the method of cases in ethics, judgements that turn out to be totally unreliable. The threat is obvious - the method of cases appeals to intuitions about the moral relevance of certain features of a described case as authoritative, and we are now presented with evidence that granting such authority would be extremely naïve.

Two instances stand out. The first is the evidence that we unconsciously manipulate the data before us, overrating the importance and value of certain features and underrating or ignoring others. We play up what we take to be the negative features of other people and the positive features of ourselves while not being aware of doing so. This leads us to expect that we would react positively to cases or features of cases that reflect well on the way we ourselves behave - reinforcing our positive self-image, while downplaying the importance of features that would not reflect well on us. Such bias in our intuitive responses would be clearly detrimental to any objective authority those 
intuitions could claim to have. And such a bias is precisely what does emerge in these and other studies.

The second most strikingly relevant feature of the research in question is the evidence that we are unreliable in diagnosing which features of a situation actually play a role in causing our affective responses and related value judgements. In the method of cases where a fictional example is constructed to aid our response to another case, we are required to judge which features of the new case are morally relevant so that we can say the same of the old case. What evidence like that of the shoppers or the respondents to the novel passage suggests is that we are not very good at diagnosing which features of the situation really are affecting our response, and thereby providing evidence of their moral relevance - even when we are sure that we do know. I argued that the evidence for systematic self-delusion suggests that our intuitions are a poor guide to predicting how we would behave, but it appears they are an even poorer guide to which features of a situation are actually morally relevant or important.

Two comments need to be added to those last few claims. You might be tempted to point out that the evidence I have outlined concerns judgements about the quality of clothes and our emotional responses, and that such affective responses do not amount to the moral intuitions that are at stake in the method of cases. In this way, you might suggest that my argument misses its target. But while it is true that the evidence is of affective responses and not moral judgements per se, it remains the case that one does not need to be an emotivist to realize that those two phenomena are intimately related. It is not just a coincidence that the features of the situation which I take to be wrong are those which disgust me. It seems to me that (whatever it is) that relation is close enough for the onus to be on the objector to explain how they are crucially different such that our moral judgements remain untouched when our affective ones are shown to be systematically unreliable.

The second comment is to head off another possible objection. You might also be tempted to argue that once we are aware of the psychological tendencies exposed here, we can learn to discount for them, and thus respond objectively. But it is not at all clear that we could do that. The research suggests that these self-deceptive tendencies are systematic. Moreover, the work of Kahneman and Tversky on judgement under conditions of uncertainty makes it fairly clear that, in similar circumstances, being faced with evidence that your intuitions are unreliable does not in any way affect your degree of certainty with respect to further intuitions. More recent work by Wilson, Centerbar and Brekke (2002) reinforces the conclusion that we simply do not have the psychological tools to effectively spot and decontaminate our biases. ${ }^{4}$

\section{Section 5: A defence for metaphysics}

The method of cases in both metaphysics and ethics thus appears vulnerable to the charge that it ascribes an authority to our intuitions that we have reason to deny. Evidence concerning the psychological patterns of humans suggests that our reported intuitions are not a reliable resource. However, I want to argue that the threat is mitigated where metaphysics is concerned because the sort of authority ascribed to intuitions there is crucially different from that in ethics.

The problem that empirical research raised for the method was that it showed that our intuitive responses as to how we would behave if we were in the situation de-

4 I discuss this in more detail in Beck 2006. In that paper I also present a similar (but more detailed) defence of the method of cases in metaphysics to the one which follows. 
scribed were unreliable. The evidence of our systematic self-delusion militates against our being able to make any such reliable prediction; it shows that what we think we would say is no guide to what we would say. But if we (along with tradition) understand the task of the method of cases as being to distinguish the essential from the non-essential features of one of our concepts, or as attempting to reveal the relative importance of the various principles that underlie our application of a concept, then we do not have to know what we would say in the situation in order to carry out the task. It is our response, given our present belief-system, not in some other belief-system that matters: we are being asked, 'does the concept as it stands allow such-and-such or apply in such-and-such conditions?' What this means is that it does not matter that what you think you would say is not a reliable guide to what you would actually say. The essential conditions implicit in your current application of a concept are to be found in what you think you would say - what you would say (if we had some reliable way of finding that out) might well only reveal how changing circumstances happened to affect how you applied the concept. The thought experimenter is not in the business of speculating on how concepts can change and be changed, though, but in the business of investigating them as they are now.

The argument from empirical psychology turns on an envisaged requirement of the method of cases that our intuitions carry what we can call epistemic authority - that they are reliable indicators of reality. It then sets about showing that our intuitions about ourselves fail to meet this requirement. My response is that thought-experiments like Locke's do not require epistemic authority of our intuitions, but rather what we might call representational authority. ${ }^{5}$ They are required only to draw out what we think about ourselves - even if we are wrong about why we think that - to achieve their purpose. As long as they produce responses that do carry representational authority that is, as long as the subjects of the experiment are not misleading the thought-experimenter as to their experienced intuitions - they stand to succeed, regardless of whether these representations match up to any facts about ourselves.

A parallel argument does not present itself for ethics; or, at least, there is only a parallel argument for a certain understanding of ethics. Our intuitive responses to cases like Thomson's and Williams's are not merely being taken as data concerning our conceptual system, but as data concerning moral issues themselves. They are required to have some sort of epistemic authority if they are to do the work moral philosophy requires of them. In those cases we are attempting to establish what we ought to think, not simply what we do think. In metaphysics, the method of cases is not out to discover metaphysical truth, but to contribute to making clear what it is that we are trying to discover the truth about - to clear the ground about what features we take reality to have. It is a further step to discover whether reality actually has those features, and that is not a task we can plausibly set for the method of cases. ${ }^{6}$

These claims do need some qualification, however. I think it would be understandable for you to come to Williams's defence here by arguing that what he wants out of Jim and the Indians is very much like what I want out of Locke's thought-experiment. Williams's case can be read as looking for how we actually use the word "right", and arguing that we do not use it in the way that utilitarians say we do. If you understand

5 This corresponds to John Christman's distinction between epistemic and personal authority (Christman 2005: 344-5).

6 I am not saying that thought-experiments have never been held to reveal metaphysical truth in the sense under discussion - but the fact that some philosophers have misused them does not damn the method. 
that as what ethics is out to do (and it is plausible to read Williams in that way), then my arguments are at your disposal. But that understanding of ethics is not what underpins most of applied ethics, and it is not the sort of ethics that attracts the big research funds. My argument is with any use of cases as a guide to moral truth.

\section{Section 6: The relativity of intuitions}

It is regularly argued in introductory texts that the fact that individuals and cultures have different and conflicting moral values does not mean that there are no general moral principles or truths. Of course, those texts are quite correct in this contention. But on the other side, it offers no help when it comes to matters of method. It is a fact that people do have different moral beliefs and also a fact that they have different intuitive responses to cases. This extends from vast and deep chasms between cultures to diverse student responses in the same philosophy class. Yet if the method of cases is to be successful in revealing moral truths, a basic requirement is that the data it works on - intuitive responses - be uniform in the way that observation supplies uniform data in its field. Any lack of uniformity will require systematic explanation. And here the prospects for the method of cases (certainly in ethics) look bleak. There simply is no theory available that can provide a plausible account of which moral intuitions are to be trusted and thus revelatory, and why that is the case for these intuitions and not others.

We might well then ask whether the same does not hold for the use of cases in metaphysics. Some philosophers have argued this - Raymond Martin has articulated exactly this misgiving concerning the personal identity debate (Martin 1988: 62-3). It is just a fact, he says, that different people respond differently to puzzle cases. Thus we might use cases to investigate what matters in survival to a particular individual, but the method cannot support conclusions about what ought rationally matter to everyone and that is what philosophers like Locke and Parfit (1984) set out to establish in the personal identity debate. Martin labels their enterprise "survival-value imperialism". Carol Rovane expresses a similar scepticism towards the method in her book The Bounds of Reason (1998). ${ }^{7}$ She contends that the method of cases would work in the personal identity debate only if we all had the same intuitive responses, and holds that we do not.

While I think that neither Rovane's nor Martin's arguments are unproblematic, I will not take issue with those details here. ${ }^{8}$ Rather, I wish to argue the general point that even if different people do respond differently to a given case, that does not by itself affect the method, at least, not if the method of cases used here is understood as outlined in the previous section. The aim of the method is not to directly reveal absolute metaphysical truth, an aim that would be affected by discrepancy in responses. It is rather to reveal the relative importance of the various implicit principles that play roles in our application of a concept - in this case, the principles underlying the concept same person. It might well be true, then, that different responses to cases reflect different underlying principles. Consistently different responses would mean that there are different concepts in operation - that the individuals concerned do not share the same

7 She writes, "Such persons - that is, persons whose intuitions are either exclusively Lockean or exclusively animalist - might be optimistic about the prospects for a thought experimental determination of the condition of personal identity. But such a determination would be forthcoming only if we all had consistent intuitions, and moreover, we all had the same consistent intuitions" (Rovane 1998: 44).

8 I do respond to Martin's arguments in Beck 2000. 
concept of person. (Presumably there will be enough overlap for them to realize that they are discussing the same subject, or the issue would not arise at all.) In certain contexts, this would render the method of cases useless - it would certainly undermine the power of an appeal to cases to change moral opinions, for instance.

It does not make the method in metaphysics pointless, however. Our responses to cases reveal which principles are most important in our application of a concept. By careful use of the method we can provide an analysis of what sort of thing we understand a person to be. ${ }^{9}$ That the responses of others show that they understand a person to be something different or that they have no belief that any such thing exists does not affect this result. That is because the question of whether there is any such thing is one that is susceptible to systematic answer in just the sort of way that was not available in explaining the provenance of moral intuitions. The question is, can we locate persons - as characterised by the results of our responses to cases - in the ingredients of the world offered to us by the more solidly-founded results of scientific enquiry? If we cannot, we must accept that there are ultimately no such things despite their importance to our moral and legal institutions. If we can, then we have in these persons an interesting and important feature of the world.

Nichols, Stich and Weinberg (2003) have suggested that the psychological biases of professional philosophers affecting their intuitions may yield a concept of knowledge that is peculiar to white, Western males and the fact that those white Western males feel it is a special concept does not make it one. As a result they suggest that problems affecting this concept raised by the sceptical tradition familiar to those philosophers may not really be problems that are at all significant. This is in many ways the problem for epistemology analogous to the problem that I have raised for views dependent on our intuitions in ethics. But the differences between it and that in metaphysics serve to reinforce my response of the previous paragraph. Nichols et al's challenge requires that sceptics and their opponents establish the special nature of knowledge as they conceive it, and that stands to be a task fraught with problems. ${ }^{10}$ There are also problems in locating persons as we conceive them in the more basic features of the world, but that is a much clearer and more down-to-earth task than that set by the challenge in epistemology.

I do not believe that this leaves my position open to Martin's charge of imperialism, either. It is not only our concept (whoever we may be) that can find better grounding. The conflicting concepts of others may well find such grounding with the same results - their intuitions would have isolated an important feature of the world on which we have been missing out, and to which we must now pay attention, perhaps at the expense our own prejudices.

\section{Conclusion}

Although some philosophers have suggested there are alternative ways, I do not see how the personal identity debate or the practice of ethics in philosophy can continue without the use of imaginary cases, and a reliance on our intuitions. If a theory does

9 By "careful use" I am excluding responses to cases that turn on a misunderstanding of the description of the case, or responses based on irrelevant factors. Here I have in mind instances such as people asserting that they would not allow themselves to be subjected to the brain-state-transfer device, not because they think they could not survive that process (the belief the experimenter reads a negative response as revealing) but because they are scared that it would malfunction.

10 While I say this, I agree with Sosa that that the problems are not nearly as great as envisaged by Nichols et al (Sosa 2009). 
not meet your intuitions with regard to specific cases, how can you accept it with any sort of sincerity? But while we may be tied to the use of the method of cases, I think moral philosophers should be much less happy about this than metaphysicians.

\section{References}

Baker, L.R. 2000. Persons and Bodies. New York: Cambridge University Press.

Beck, S. 2000. 'Points of concern'. Theoria, 96, pp121-130.

Beck, S. 2006. 'These bizarre fictions: thought-experiments, our psychology and our selves'. Philosophical Papers, 35(1), pp29-54.

Brown, J. 1986. 'Evaluations of self and others: self-enhancement biases in social judgements'. Social Cognition, 4, pp353-76.

Christman, J. 2005. 'Autonomy, Self-Knowledge and Liberal Legitimacy', in Christman, J. \& Anderson, J. (eds.). Autonomy and the challenges to liberalism. Cambridge: Cambridge University Press.

Doris, J. 2002. Lack of character. Cambridge: Cambridge University Press.

Evans, J. 1990. Bias in human reasoning: causes and consequences. Hove: Lawrence Erlbaum Associates.

Jackson, F. 1998. From metaphysics to ethics. Oxford: Oxford University Press.

Kagan, S. 2001. 'Thinking about cases', Social Philosophy and Policy ,18, pp44-63.

Lewinsohn, P., Mischel, W., Chaplin, W., \& Barton, R.1980. 'Social competence and depression' Journal of Abnormal Psychology, 89, pp203-12.

Leibniz, G. 1981. New essays concerning human understanding. Remnant, P. \& Bennett, J. (trans. \& ed.). Cambridge: Cambridge University Press.

Locke, J. 1975. 'Of identity and diversity', in Perry, J. (ed.). Personal Identity. Berkeley: University of California Press.

Martin, R. 1998. Self-concern. New York: Cambridge University Press.

Nichols, S. 2004. Sentimental rules. Oxford: Oxford University Press.

Nichols, S., Stich, S., \& Weinberg, J. 2003. 'Metaskepticism: meditations on ethno-epistemology', in Luper, S. (ed.). The skeptics. London: Ashgate.

Nisbett, R., \& Ross, L. 1980. Human inference. Englewood-Cliffs, NJ: Prentice-Hall.

Parfit, D. 1984. Reasons and persons. Oxford: Clarendon Press.

Rovane, C. 1998. The bounds of agency. Princeton: Princeton University Press.

Shoemaker, S., \& Swinburne, R. 1984. Personal identity. Oxford: Blackwell.

Sober, E. 2001. Core questions in philosophy. Upper Saddle River: Prentice-Hall.

Sosa, E. 2009. 'A defense of the use of intuitions in philosophy', in Bishop, M. and Murphy, D. (eds.). Stich and his critics. Oxford: Blackwell.

Taylor, S. \& Brown, J. 1988. 'Illusion and well-being', Psychological Bulletin, 103, pp193-210.

Thomson, J. 1979. ‘A defence of abortion', in Rachels, J. (ed.). Moral problems. New York: Harper and Row.

Thomson, J. 1986. Rights, Restitution, and Risk. Parent, W. (ed.). Cambridge, Mass.: Harvard University Press. 
Williams, B. 1973a. 'The self and the future', in Problems of the self. Cambridge: Cambridge University Press.

Williams, B. 1973b. 'A critique of utilitarianism', in Smart, J. \& Williams, B. Utilitarianism: for and against. Cambridge: Cambridge University Press.

Wilson, T., Centerbar, D., \& Brekke, N. 2002. 'Mental contamination and the debiasing problem', in Gilovich, T., Griffin, D. \& Kahneman, D. (eds.). Heuristics and Biases. New York: Cambridge University Press. 